University of the Pacific

Scholarly Commons

$12-23-2015$

\title{
The transient receptor potential vanilloid 4 channel modulates uterine tone during pregnancy
}

\author{
Lihua Ying \\ Stanford University School of Medicine \\ Margaux Becard \\ Pôle Femme Mère Enfant \\ Deirdre Lyell \\ Stanford University School of Medicine \\ Xiaoyuan Han \\ Stanford University School of Medicine, xhan@pacific.edu \\ Linda Shortliffe \\ Stanford University School of Medicine
}

See next page for additional authors

Follow this and additional works at: https://scholarlycommons.pacific.edu/dugoni-facarticles

Part of the Medicine and Health Sciences Commons

\section{Recommended Citation}

Ying, L., Becard, M., Lyell, D., Han, X., Shortliffe, L., Husted, C. I., Alvira, C., \& Cornfield, D. N. (2015). The transient receptor potential vanilloid 4 channel modulates uterine tone during pregnancy. Science Translational Medicine, 7(319), DOI: 10.1126/scitransImed.aad0376 https://scholarlycommons.pacific.edu/dugoni-facarticles/722

This Article is brought to you for free and open access by the All Faculty Scholarship at Scholarly Commons. It has been accepted for inclusion in All Dugoni School of Dentistry Faculty Articles by an authorized administrator of Scholarly Commons. For more information, please contact mgibney@pacific.edu. 


\section{Authors}

Lihua Ying, Margaux Becard, Deirdre Lyell, Xiaoyuan Han, Linda Shortliffe, Cristiana losef Husted, Cristina M. Alvira, and David N. Cornfield 


\title{
The transient receptor potential vanilloid 4 channel modulates uterine tone during pregnancy
}

\author{
Lihua Ying, ${ }^{1}$ Margaux Becard, ${ }^{2}$ Deirdre Lyell, ${ }^{3}$ Xiaoyuan Han, ${ }^{4}$ Linda Shortliffe, ${ }^{4}$ \\ Cristiana losef Husted, ${ }^{5}$ Cristina M. Alvira, ${ }^{1,6 *}$ David N. Cornfield ${ }^{1,6,7 *{ }_{*}^{+}}$
}

The importance of gaining insight into the mechanisms underlying uterine quiescence and contractility is highlighted by the absence of an effective strategy to prevent or treat preterm labor, the greatest cause of perinatal mortality and morbidity worldwide. Although current evidence suggests that in myometrial smooth muscle cells (mSMCs) calcium homeostasis is modulated near term to promote uterine contractility, the efficacy of blocking voltage-operated calcium channels is limited by dose-related cardiovascular side effects. Thus, we considered whether uterine contractility might be modulated by calcium entry via transient receptor potential vanilloid 4 (TRPV4) channels. In mSMC, TRPV4 gene and protein expression increased with gestation, and TRPV4-mediated $\mathrm{Ca}^{2+}$ entry and contractility were increased in mSMC from pregnant compared to nonpregnant rats. Cell membrane TRPV4 expression was specifically increased, whereas the expression of $\beta$-arrestin-1 and $\beta$-arrestin-2, molecules that can sequester TRPV4 in the cytoplasm, decreased. Physical interaction of $\beta$-arrestin-2 and TRPV4 was apparent in nonpregnant, but absent in pregnant, mouse uterus. Moreover, direct pharmacologic activation of TRPV4 increased uterine contraction, but oxytocin-induced myometrial contraction was blocked by pharmacologic inhibition of TRPV4 and decreased in mice with global deletion of TRPV4. Finally, TRPV4 channel blockade prolonged pregnancy in two distinct in vivo murine models of preterm labor, whereas the absence of either $\beta$-arrestin-1 or $\beta$-arrestin- 2 increased susceptibility to preterm labor. These data suggest that TRPV4 channel activity modulates uterine contractility and might represent a therapeutic target to address preterm labor.

\section{INTRODUCTION}

In mammalian biology, the uterus must first remain quiescent to accommodate a growing organism in utero, and then contract powerfully to expel the mature fetus for relatively independent air-breathing life. Despite the clear importance of these divergent but biologically imperative uterine roles, the mechanisms regulating the switch between the myometrial quiescence of pregnancy and the myometrial contraction of labor are largely unknown. The importance of gaining insight into the mechanisms that underlie the dual role of the myometrium is highlighted by the lack of effective strategies to either prevent or treat preterm labor, a substantial cause of perinatal mortality and morbidity $(1,2)$.

The physiologic signals that underlie the rhythmic, repeated uterine contractions that characterize labor remain incompletely understood. Among the theories related to the onset of labor are changes in myometrial progesterone and estrogen receptors (3), or the release of amniotic fluid from the amnion (4). Moreover, in most mammalian species, progesterone withdrawal seems to play a central role in the onset of labor (5).

Current evidence suggests that myometrial smooth muscle cell (mSMC) $\mathrm{Ca}^{2+}$ homeostasis is modulated near term to promote uterine contractility. In the human myometrium, entry of extracellular $\mathrm{Ca}^{2+}$ is essential for the initiation and maintenance of spontaneous and agonist-induced rhythmic contractions $(6,7)$. Binding of oxytocin to the oxytocin receptors promotes

'Center for Excellence in Pulmonary Biology, Stanford University Medical School, Stanford, CA 94305, USA. ²Pôle Mère, Département de Gynécologie Obstétrique, Centre Hospitalier de Calais, Calais 62100, France. ${ }^{3}$ Departments of Pediatrics and Obstetrics and Gynecology, Stanford University Medical School, Stanford, CA 94305, USA. ${ }^{4}$ Department of Urology, Stanford University Medical School, Stanford, CA 94305, USA. ${ }^{5}$ Department of Biochemistry and Molecular Biology, School of Medicine, University of Nevada, Reno, CA 89557, USA. 'Divisions of Pulmonary, Asthma and Sleep Medicine, Stanford University Medical School, Stanford, CA 94305, USA. 'Division of Critical Care Medicine, Stanford University Medical School, Stanford, CA 94305, USA.

*These authors are co-senior authors.

tCorresponding author. E-mail: cornfield@stanford.edu uterine contractility by increasing receptor-mediated calcium $\left(\mathrm{Ca}^{2+}\right)$ entry (8). Although the current paradigm suggests that extracellular $\mathrm{Ca}^{2+}$ enters mSMC predominantly via L-type voltage-gated calcium channels (9), L-type $\mathrm{Ca}^{2+}$ channel blockers tested in clinical trials for the prevention of preterm labor have neither prolonged gestation nor improved adverse perinatal outcomes, owing in part to dose-related side effects $(2,10)$. The absence of a definitive therapeutic benefit with L-type $\mathrm{Ca}^{2+}$ channel blockade suggests that $\mathrm{Ca}^{2+}$ may also enter the myometrium through an alternative route.

Thus, we considered whether $\mathrm{Ca}^{2+}$ might gain entry into the mSMC via transient receptor potential vanilloid (TRPV) channels. TRPV channels belong to the vanilloid subfamily of the TRP channel family, a group of nonselective cation channels permeable to sodium, $\mathrm{Ca}^{2+}$, and magnesium. TRPV channels are widely expressed in the central and peripheral nervous system, epithelial cells, vascular smooth muscle cells (11), and other mesenchyme-derived cells (12). In particular, the TRPV4 channel is activated in response to cell swelling, shear stress, moderate heating, hypotonic stress (13), and phorbol ester (14). Mice lacking TRPV4 are less sensitive to osmotic stress and noxious mechanical and painful stimuli (15). Although TRPV4 is expressed in the murine uterus (16), TRPV4-null mice seem to reproduce normally. However, whether these mice are resistant to stimuli known to induce preterm labor remains entirely unknown.

To determine whether the TRPV4 channel might play a role in uterine contractility, we undertook a series of experiments in rats, mice, and humans. We demonstrated that TRPV4 channel gene and protein expression increases with gestation, proportionally more in the membrane relative to the whole cell. We also demonstrated that TRPV4 expression is greater in uterine tissue of pregnant, compared to nonpregnant, women. Moreover, we used microfluorimetry, myography, and collagen gel contraction assays to demonstrate a role for the TRPV4 channel in oxytocin-induced increases of mSMC cytosolic calcium and uterine contraction. As further proof of principle, we used murine models of 
preterm labor to show that pharmacologic blockade of the TRPV4 channel can effectively prolong pregnancy.

\section{RESULTS}

\section{TRPV4 expression and membrane localization increase during pregnancy}

Among the TRPV channels, TRPV4 is activated by stretch, swelling, heat, or pressure (17-19), physiologic stimuli that are likely to play a role in uterine contractility. Thus, to determine whether TRPV4 channels modulate myometrial tone during pregnancy, we used quantitative polymerase chain reaction (qPCR) to measure Trpv4 gene expression in primary mSMCs obtained from rats under control conditions (nonpregnant), at specific time points during pregnancy (D7 to D21) and postpartum. During pregnancy, Trpv4 gene expression in $\mathrm{mSMC}$

A

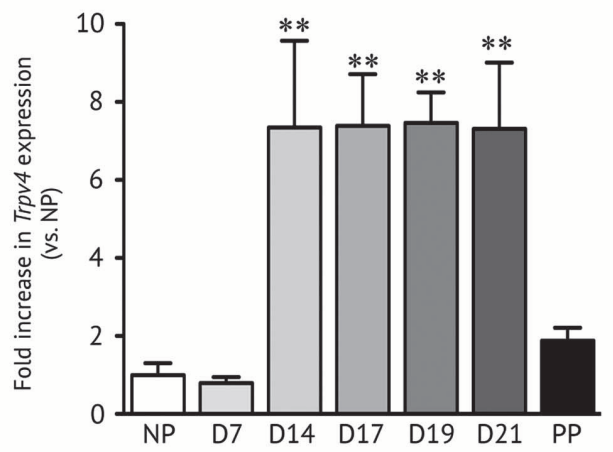

D
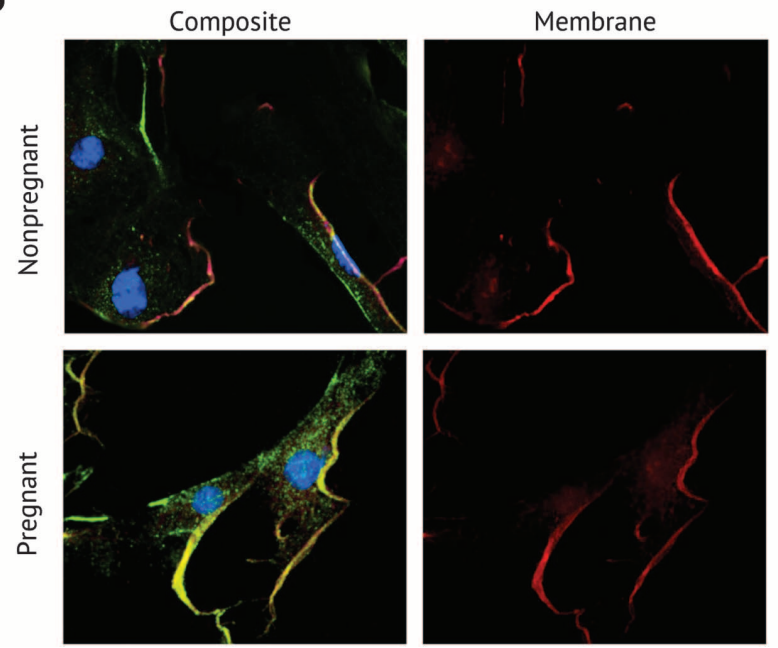

Fig. 1. TRPV4 expression and cell membrane localization increase during late gestation. (A) Relative Trpv4 gene expression was determined by $\mathrm{qPCR}$ in $\mathrm{mSMC}$ isolated from nonpregnant rats and rats at various stages of pregnancy or postpartum (PP). $n=6$ samples per group, with each sample containing cells from at least three animals; ${ }^{* *} P=0.0094$ for D14, ${ }^{* *} P=$ 0.0087 for $\mathrm{D} 17,{ }^{* *} P=0.0075$ for $\mathrm{D} 19$, and ${ }^{*} P=0.01 \mathrm{D} 21$ versus nonpregnant (NP) via one-way analysis of variance (ANOVA). (B and C) Western immunoblot to detect TRPV4 protein in (B) whole-cell lysates and (C) membrane fractions of myometrial SMC isolated from nonpregnant and pregnant markedly increased (Fig. 1A). By day 14 of gestation, Trpv4 gene expression in pregnant $\mathrm{mSMC}$ was more than sixfold greater than in nonpregnant mSMC (white bar) and remained elevated throughout the remainder of pregnancy. However, after parturition, Trpv4 expression decreased, with postpartum expression no different than that found in nonpregnant mSMC.

We next determined whether a similar up-regulation of TRPV4 occurred in the uterus of pregnant women. In keeping with the results in the pregnant rat, TRPV4 gene expression was almost 1000-fold greater in pregnant compared to nonpregnant human uterine tissue (fig. S1). However, owing to limitations in sample procurement, the results must be considered in light of the substantial difference $(P<0.001)$ in the mean age of the pregnant women ( $33 \pm 3$ years) compared to nonpregnant women ( $56 \pm 4$ years).

In pregnant rats, the increase in Trpv4 gene expression was associated with an increase in TRPV4 protein expression. TRPV4 protein was about 1.5 -fold higher in whole-cell lysates of mSMC obtained from pregnant
B

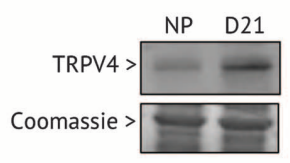

C

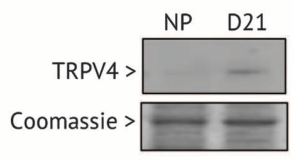

TRPV4
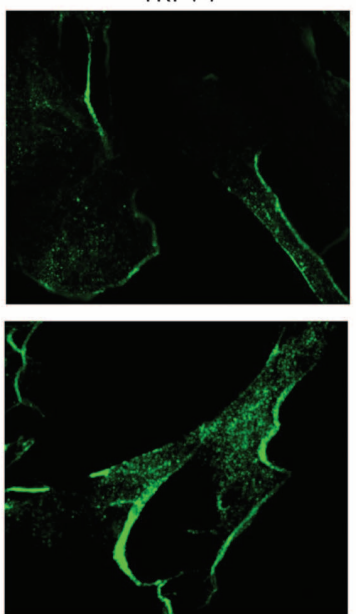
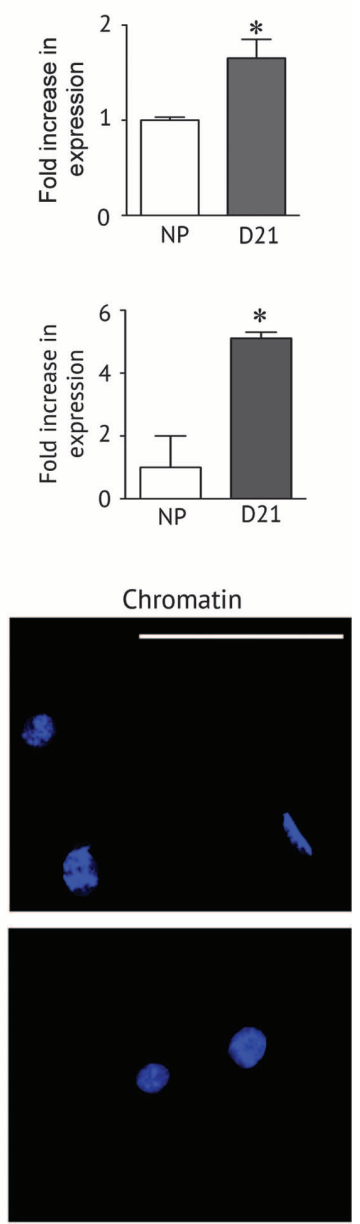

(D21) rats normalized to Coomassie staining. Quantification shown as bar graphs on the right, expressed as fold increase in expression versus nonpregnant; $n=4$ samples containing cells obtained from a total of 12 animals; ${ }^{*} P=0.0286$ for (B) and ${ }^{*} P=0.0265$ for $(C)$ via Mann-Whitney $U$ test. (D) Immunocytochemistry of rat mSMC obtained from nonpregnant and D21 rats, shown with the CellMask (Invitrogen) plasma membrane stain (red), 4,6diamidino-2-phenylindole (DAPI) (blue), and a primary antibody to detect TRPV4 (green), with the presence of TRPV4 on the plasma membrane evidenced by the colocalization signal (yellow). Scale bar, $50 \mu \mathrm{m}$. 
rats at day 21 of gestation (D21) compared to nonpregnant mSMC (Fig. 1B). Notably, TRPV4 protein was fivefold higher in the membrane fraction of the pregnant versus nonpregnant mSMC (Fig. 1C), suggesting that changes in both TRPV4 expression and subcellular localization occur during pregnancy. To further evaluate whether the cell membrane expression of TRPV4 in mSMC changes during gestation, mSMCs from pregnant and nonpregnant rats were immunostained to detect the presence of TRPV4 protein in combination with a plasma membrane selective dye. With this method, the overall intensity of TRPV4 membrane staining was higher in the cells from pregnant rats (Fig. 1D), consistent with increased expression of TRPV4 protein expression noted in the membrane fraction. Together, these data suggest that during pregnancy, increases in TRPV4 expression in combination with a putative increase in TRPV4 channel trafficking to the plasma membrane may facilitate enhanced activation of the channel during parturition $(20,21)$.

\section{Activation of TRPV channels increases cytosolic calcium more in $\mathrm{mSMC}$ from pregnant than nonpregnant rats}

We evaluated the effect of TRPV channel activation on mSMC cytosolic calcium $\left(\left[\mathrm{Ca}^{2+}\right]_{\mathrm{i}}\right)$ with the calcium-sensitive fluorophore fura-2. Pharmacologic TRPV channel activation with the selective TRPV4 agonist $4 \alpha-$ phorbol 12,13-didecanoate ( $4 \alpha \mathrm{PDD})(22)$ caused a sustained increase in $\left[\mathrm{Ca}^{2+}\right]_{\mathrm{i}}$ in mSMC from both pregnant and nonpregnant rats (Fig. 2A). However, the maximal increase in $\left[\mathrm{Ca}^{2+}\right]_{\mathrm{i}}$ was greater in pregnant mSMC as compared to nonpregnant mSMC ( ${ }^{* *} P=0.0012$; Fig. $\left.2 \mathrm{~B}\right)$. In further experiments, pregnant mSMCs were pretreated with either vehicle or the nonselective TRPV inhibitor ruthenium red (23) before stimulation with $4 \alpha \mathrm{PDD}$. Ruthenium red completely blocked the $4 \alpha \mathrm{PDD}-$ induced increase in $\left[\mathrm{Ca}^{2+}\right]_{\mathrm{i}}$ in the pregnant cells (Fig. 2, C and D), implying that in mSMC from pregnant rats, $4 \alpha \mathrm{PDD}$ increases $\left[\mathrm{Ca}^{2+}\right]_{\mathrm{i}}$ via TRPV channel activation. In contrast, in nonpregnant mSMC (Fig. $2, \mathrm{E}$ and $\mathrm{F})$, the relatively smaller $4 \alpha \mathrm{PDD}$-induced increase in $\left[\mathrm{Ca}^{2+}\right]_{i}$ was not attenuated by ruthenium red, suggesting that calcium increases are primarily attributable to mechanisms other than TRPV channels in nonpregnant $\mathrm{mSMC}$.

\section{The expression of $\beta$-arrestin proteins and their physical interaction with TRPV4 decrease during pregnancy}

Dynamic protein-protein interactions can modify ion channel activity through subcellular trafficking. For example, TRPV4 can interact with $\beta$ arrestins (21), a family of proteins that functionally down-regulate transmembrane receptors by enhancing receptor internalization via endocytosis $(21,24)$. In vascular SMC, $\beta$-arrestin- 1 and $\beta$-arrestin- 2 can modulate TRPV4 activity via ubiquitination and subsequent endocytosis (25).

To further detail the intracellular movement of TRPV4 during pregnancy, we evaluated frozen sections of uterine tissue from nonpregnant and pregnant mice by confocal microscopy. TRPV4 was present in cells and tissue in both pregnant and nonpregnant mice (Fig. 3A). However, in images of samples derived from pregnant mice, the TRPV4 staining was much more intense at the membrane and with a linear orientation and radial distribution, as compared with the images from the nonpregnant mice, where TRPV4 staining was more diffuse, nonlinear, and distributed more centrally.

To more fully explore the hypothesis that trafficking of TRPV4 is altered in $\mathrm{mSMC}$ during pregnancy, we investigated whether the increased membrane expression of TRPV4 in pregnant mSMC was associated with changes in $\beta$-arrestin- 1 or $\beta$-arrestin- 2 expression. Protein expression of both $\beta$-arrestin- 1 and $\beta$-arrestin- 2 appeared to be decreased in $\mathrm{mSMC}$
A

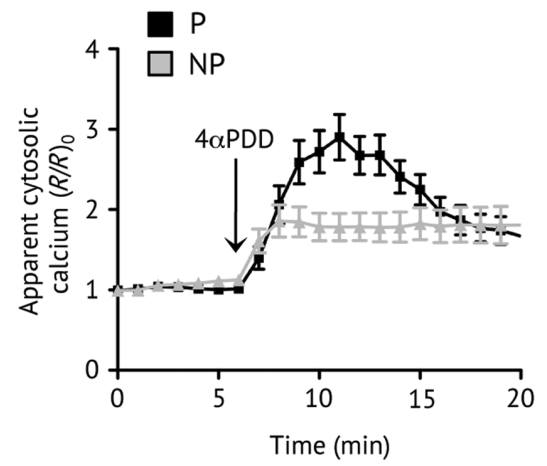

B

C

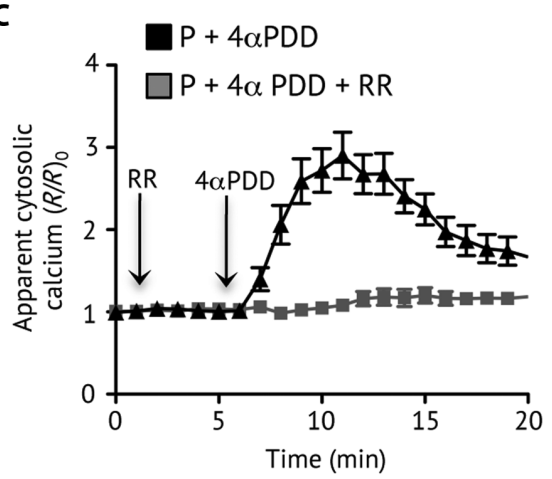

D

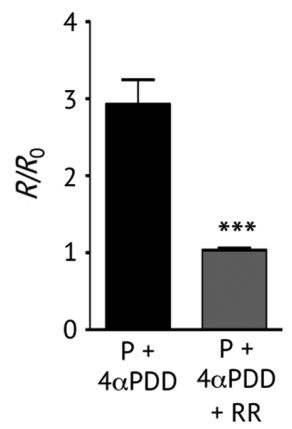

$\mathbf{E}$

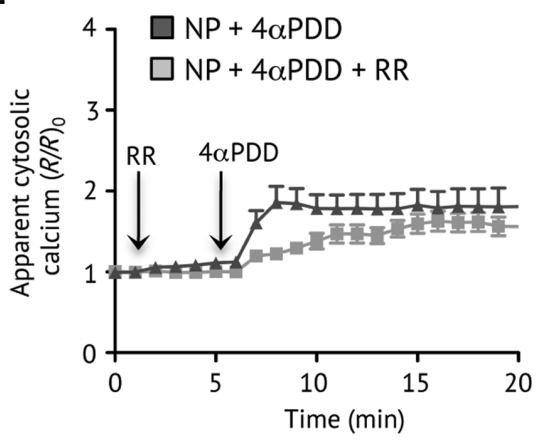

$\mathbf{F}$

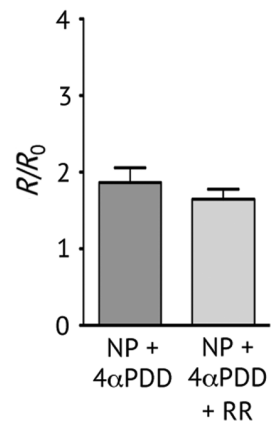

Fig. 2. TRPV channel activation increases cytosolic calcium in pregnant more than nonpregnant $\mathbf{m S M C}$. (A) mSMCs from nonpregnant (gray) and D21 (black) rats were loaded with fura-2, and the apparent cytosolic calcium $\left(R / R_{0}\right)$ was measured at baseline and after the addition of the TRPV channel agonist, $4 \alpha \mathrm{PDD}$ (arrow). (B) Peak cytosolic calcium $\left(R / R_{0}\right)$ in nonpregnant and D21 mSMC; $n=52$ to 86 cells and ${ }^{*} P=0.0012$ via Mann-Whitney $U$ test. (C) mSMCs from D21 pregnant $(\mathrm{P})$ rats were loaded with fura-2, and the $R / R_{0}$ induced by $4 \alpha \mathrm{PDD}$ in cells pretreated with the TRPV blocker ruthenium red (RR) was compared to cells treated with $4 \alpha \mathrm{PDD}$ alone. (D) Peak cytosolic calcium $\left(R / R_{0}\right)$ in D21 mSMC treated with $4 \alpha \mathrm{PDD}$ and either vehicle or ruthenium red; $n=52$ to 76 cells and ${ }^{* * *} P=0.004$ via Mann-Whitney $U$ test. (E) mSMCs from nonpregnant rats were loaded with fura-2, and the $R / R_{0}$ induced by $4 \alpha \mathrm{PDD}$ in cells pretreated with the TRPV blocker ruthenium red was compared to cells treated with $4 \alpha \mathrm{PDD}$ alone. (F) Peak cytosolic calcium $\left(R / R_{0}\right)$ in nonpregnant $\mathrm{mSMC}$ treated with $4 \alpha \mathrm{PDD}$ and either vehicle or ruthenium red; $n=86$ cells.

from pregnant (D19) as compared to nonpregnant mSMC (Fig. 3, B and $C$ ), although the results did not reach statistical significance. This finding suggested that decreases in $\beta$-arrestin- 1 and $\beta$-arrestin- 2 late in 
A

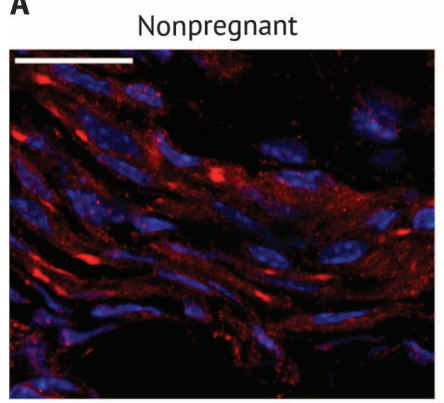

B

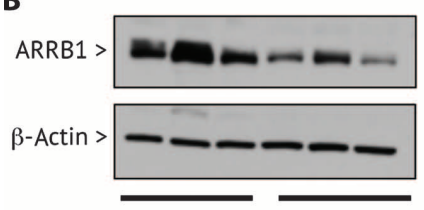

NP $\quad P$

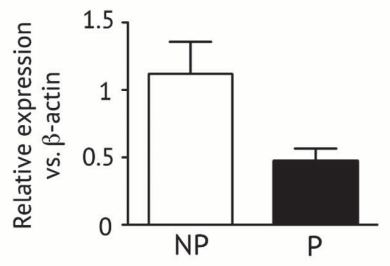

D
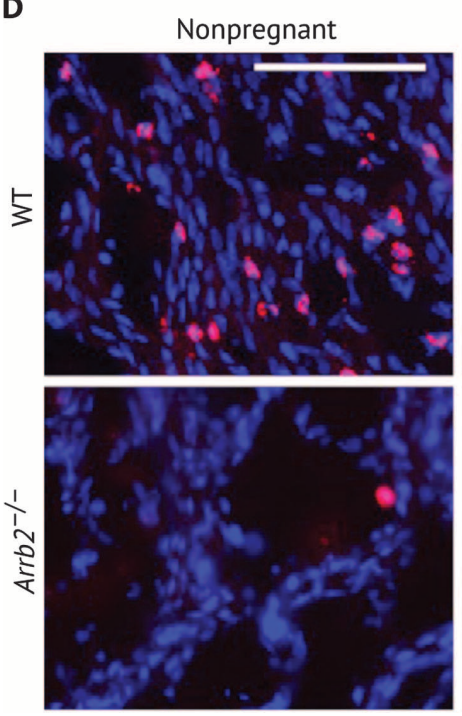

Pregnant (D19)

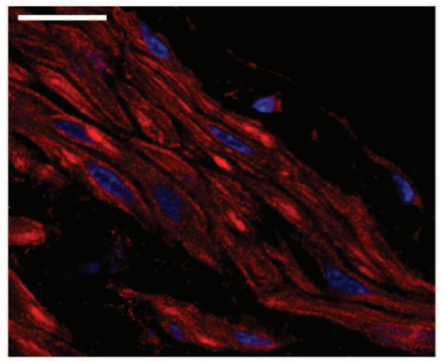

C

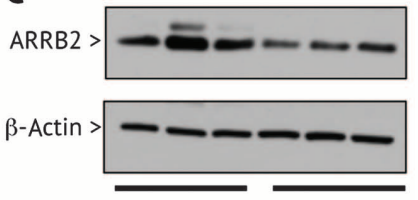

P

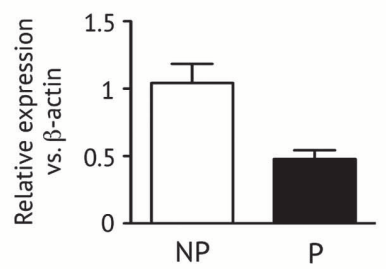

Pregnant (D19)
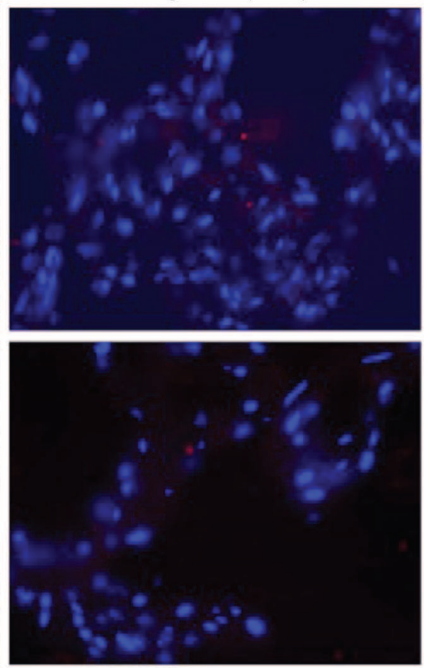

Fig. 3. The expression of $\boldsymbol{\beta}$-arrestin proteins and their physical interaction with TRPV4 decrease during pregnancy. (A) Confocal microscopy was performed on frozen myometrial tissue from both pregnant and nonpregnant mice immunostained to detect TRPV4 (red). Scale bars, $100 \mu \mathrm{m}$. (B and C) Western blotting of myometrial tissue from pregnant and nonpregnant mice to detect (B) $\beta$-arrestin1 (ARRB1) and (C) $\beta$-arrestin-2 (ARRB2), with $\beta$-actin as a loading control; $n=3$ and $P=0.10$ for both (B) and (C) via Mann-Whitney $U$ test. (D) In situ proximity ligation assay (PLA) was performed on nonpregnant and pregnant uterine tissue from wild-type (WT) and $A r r b 2^{-/-}$mice, with physical interaction of TRPV4 and ARRB2 visualized by pink staining. Tissue from $\mathrm{Arrb}^{-1-}$ mice was used as a negative control. Scale bar, $100 \mu \mathrm{m}$.

gestation may result in discrete, time-limited reductions in the ubiquitination and endocytosis of TRPV4, thereby allowing for functional increases in TRPV4 activity before parturition.

Previous work has shown that $\beta$-arrestin- 2 can bind TRPV4 in vascular SMC, thereby decreasing the amount of TRPV4 present at the cell membrane by increasing endocytosis (21). To evaluate whether TRPV4 physically interacts with $\beta$-arrestin-2, we next performed in situ PLAs, a highly sensitive test that permits the detection of protein-protein interactions in nonmodified cells. As demonstrated in Fig. 3D, physical interaction between TRPV4 and $\beta$-arrestin- 2 was present only in nonpregnant $\mathrm{mSMC}$, providing evidence for a role for $\beta$-arrestin- 2 in maintaining the TRPV4 channel within the cytosol in nonpregnant mSMC.

\section{TRPV4 activation mediates human mSMC contraction in collagen gels}

To assess the role of TRPV4 in mediating mSMC contraction, human mSMCs were included in collagen gels (26) after silencing TRPV4 expression with small interfering RNA (siRNA). Transfection of the human mSMC with anti-TRPV4 siRNA effectively depleted both TRPV4 mRNA (Fig. 4A) and protein (Fig. 4B). Collagen gels without incorporated mSMC did not contract in response to vehicle, oxytocin, or lipopolysaccharide (LPS). Collagen gels containing nontargeting control (NTC) siRNA-treated SMC contracted slightly in the absence of stimuli. Stimulation of gels containing NTC siRNA-treated mSMC with oxytocin $(100 \mathrm{mM})$ or an inflammatory stimulus (LPS, $100 \mathrm{ng} / \mathrm{ml}$ ) decreased the collagen area by $45 \pm 2 \%(P=0.022)$ and $41 \pm 2 \%$ or $(P=0.1216)$, respectively (Fig. 4 , C and D). However, neither oxytocin nor LPS induced contraction in collagen gels containingTRPV4 siRNA-treated mSMC.

\section{TRPV4 channel activity modulates uterine contractility}

To test the hypothesis that TRPV4 channel activity modulates the uterine contractile response to oxytocin, we studied the contractile response of uterine muscle strips from pregnant (day 18) wild-type mice exposed to increasing concentrations of oxytocin in the presence and absence of a specific TRPV4 channel antagonist, HC 067047. Oxytocin induced a dose-dependent increase in uterine contractility that was abrogated by pharmacologic blockade of the TRPV4 channel (Fig. 5, A and B). Similarly, the TRPV4 agonist GSK1016790A also induced a dose-dependent increase in uterine contractility (Fig. 5, C and D) that was blocked by HC 067047. Finally, as further proof of concept that TRPV4 is a key regulator of uterine contractility, the oxytocin-induced contractile response was markedly attenuated in uterine strips obtained from mice containing global deletions in TRPV4 (Trpv $4^{-{ }^{-}}$) (Fig. 5, E and F).

\section{Pharmacologic blockade of TRPV4 delays parturition in murine models of preterm labor}

To determine whether these changes in TRPV4 expression and subcellular localization have meaningful physiologic implications during pregnancy and parturition, we next performed experiments using a selective TRPV4 channel antagonist in two established murine models of preterm birth. First, we treated pregnant C57BL/6 mice with a single subcutaneous injection of either vehicle or the progesterone receptor antagonist RU-486 at day 15 of gestation (D15). RU-486-treated mice were then treated with either intraperitoneal injections of normal saline or one or more doses of the selective TRPV4 channel antagonist HC 067047 beginning 8 hours after RU-486 administration (27). Control mice exposed to vehicle instead of RU-486 delivered pups, on average, 108 hours after vehicle injection (Fig. 6A). In contrast, mice treated with RU-486 
A

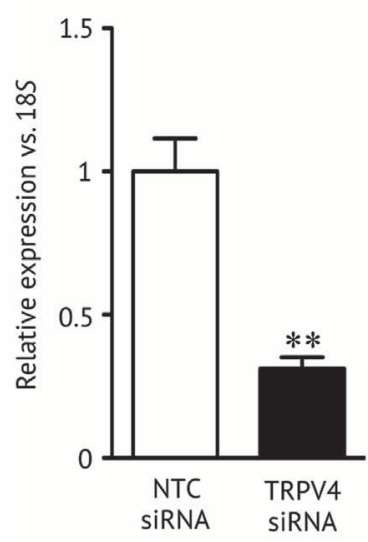

C

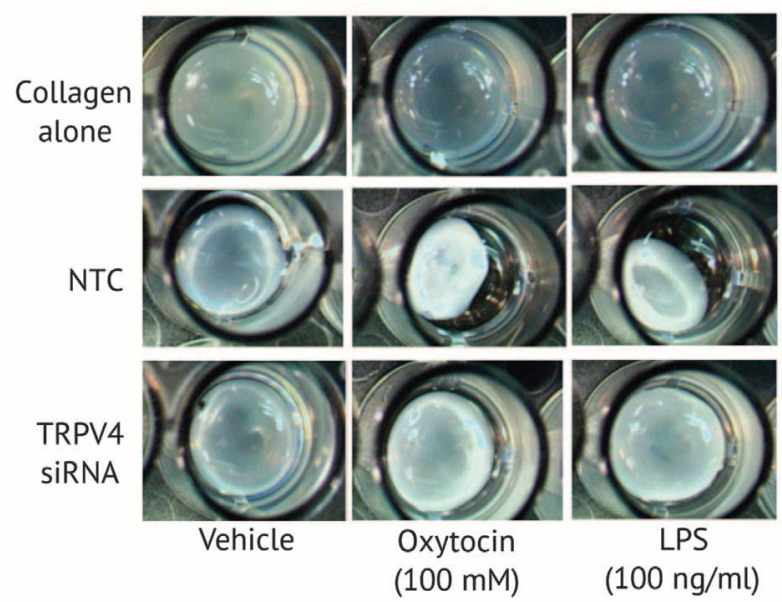

D

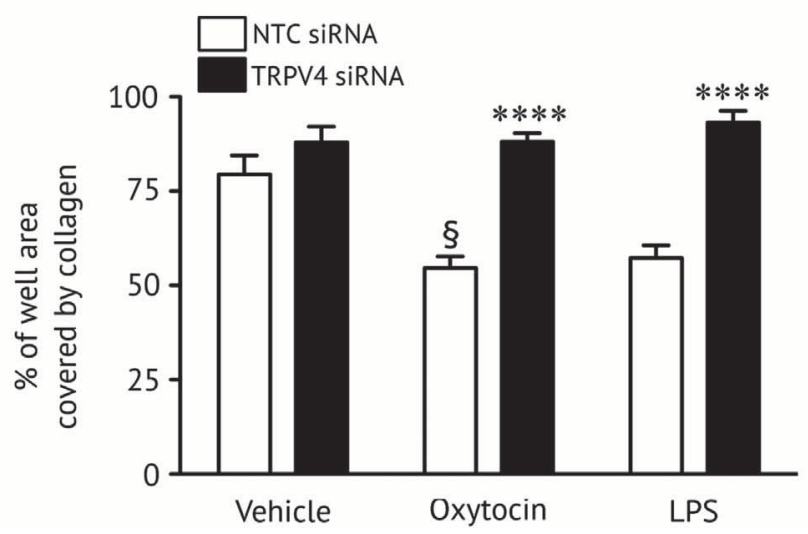

Fig. 4. Depletion of TRPV4 attenuates human mSMC contraction in response to oxytocin. (A and B) Human mSMCs were transfected with either NTC or TRPV4 siRNA, and TRPV4 gene (A) and protein (B) expression were determined. (C and D) Collagen gel contraction assays were performed with human mSMC treated with NTC or TRPV4 siRNA and stimulated with vehicle, oxytocin, or LPS. The collagen-covered area in each well was compared to the area of the well containing collagen alone and expressed as a percentage. ${ }^{\S} P=0.022$ for oxytocin-stimulated and $P=0.1216$ for LPS-stimulated NTC siRNA versus vehicle, and ${ }^{* * *} P<$ 0.0001 for both oxytocin- and LPS-stimulated TRPV4 siRNA gels versus NTC siRNA gels, via two-way ANOVA; $n=3$ to 6 for all groups. and saline delivered pups only $15 \pm 3$ hours after RU-486 injection. Although a single large dose of HC 067047 prolonged the onset of labor in the RU-486-treated mice to $27 \pm 2$ hours, this was not significantly different from the time until onset of labor in the RU-486 + saline-treated mice. However, multiple smaller doses of the TRPV4 antagonist HC 067047 significantly prolonged onset until labor in the RU-486 mice, with this group delivering pups at $63 \pm 7$ hours after RU-486 injection $(P=0.0002)$.

Inflammation and infection are well-established causes of preterm labor. Given the recent identification of TRPV4 as a proinflammatory factor (28), we hypothesized that TRPV4 blockade may be even more efficacious in an inflammatory model of preterm birth. The link between inflammation and preterm labor has been recapitulated in an established murine model of preterm labor induced by the administration of intraperitoneal LPS early in pregnancy (29). Pregnant mice received intraperitoneal injections of either phosphate-buffered saline (PBS) or LPS on D15 of pregnancy, and 8 hours later, the groups of LPS-treated mice received vehicle or either a single large dose or repeated smaller doses of HC 067047. Pregnant mice receiving LPS and vehicle delivered pups within $24 \pm 1$ hours (Fig. 6B). Although treatment with a single dose of HC 067047 had no effect on the time until delivery, treatment with multiple small doses of HC 067047 effectively prevented preterm labor induced by LPS, prolonging the time until delivery of pups to $111 \pm$ 8 hours, which was no different than control mice receiving vehicle in the absence of LPS.

\section{Loss of either $\beta$-arrestin-1 or $\beta$-arrestin- 2 heightens the susceptibility to LPS-induced preterm labor}

To further explore the mechanism whereby TRPV4 modulates uterine tone, we evaluated whether mice with deletions of either $\beta$-arrestin$1\left(\right.$ Arrb $\left.^{-1-}\right)$ or $\beta$-arrestin-2 $\left(A r r b 2^{-/-}\right)$demonstrated altered sensitivity to the induction of preterm labor. We hypothesized that the Arrb1 ${ }^{-/-}$ and $A r r b 2^{-/-}$mice would be highly susceptible to LPS-induced preterm labor, and thus, we chose to perform studies with a lower dose of LPS $(1 \mathrm{mg} / \mathrm{kg}$ ) than those used in our previous experiments. Treating wildtype mice at day 15 of pregnancy with this lower dose of LPS induced delivery of pups at $58 \pm 15$ hours after injection (Fig. 6C). Loss of either $\beta$-arrestin- 1 or $\beta$-arrestin- 2 markedly increased the susceptibility to preterm labor, with the Arrb1 $1^{-/}$mice delivering pups at $15 \pm 2$ hours after LPS injection, and Arrb2 $2^{-1-}$ mice delivering pups at $18 \pm 1$ hours after LPS injection.

\section{DISCUSSION}

Despite the clear importance of strategies to prevent preterm labor, limited understanding surrounding the fundamental biology of uterine contractility continues to constrain efforts to develop effective therapies. The present report includes evidence that in $\mathrm{mSMC}$, the TRPV4 channel plays a central role in uterine contractility. By modulating channel activity in murine models of preterm labor, we provide evidence that the TRPV4 channel has meaningful therapeutic potential in the context of both physiologic and pathophysiologic labor.

Consistent with a previous report (16), these data demonstrate that mSMC, human and murine, express TRPV4 channels. Moreover, TRPV4 expression in the uterus increases markedly in both rat and mouse during pregnancy, and TRPV4 expression on the cell membrane also increases. Our data also suggest that TRPV4 expression may 
A

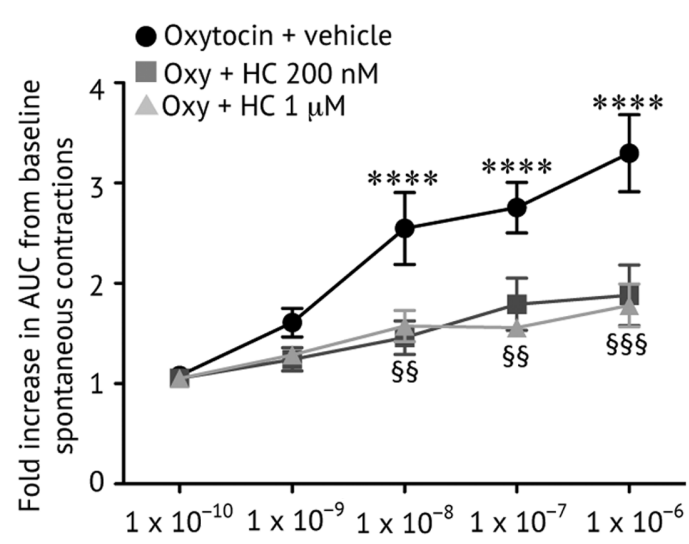

C
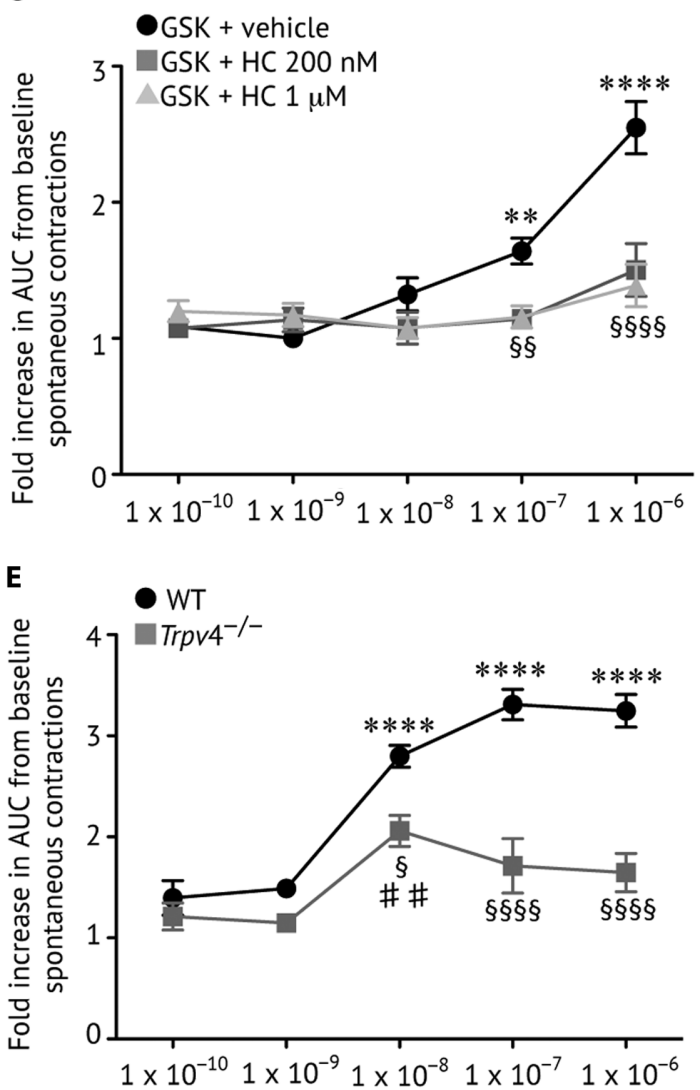

Fig. 5. TRPV4 channel activity modulates uterine contractility. (A) Myography of uterine muscle strips from pregnant WT mice at D18 was performed while incubating the strips with increasing doses of oxytocin in the presence of vehicle (black circles), $200 \mathrm{nM} \mathrm{HC} 067047$ (dark gray squares), or $1 \mu \mathrm{M} \mathrm{HC} 067047$ (light gray triangles). ${ }^{* * * *} P<0.0001$ versus $1 \times 10^{-10} \mathrm{M}$ oxytocin, ${ }^{\S \S} P=0.0086$ for $200 \mathrm{nM} \mathrm{HC} 067047$, and $P=0.022$ for $1 \mu \mathrm{M} \mathrm{HC}$ 067047 versus $1 \times 10^{-8} \mathrm{M}$ oxytocin, ${ }^{\S \S} P=0.0235$ for $200 \mathrm{nM} \mathrm{HC} 067047$ and $P=0.0034$ for $1 \mu \mathrm{M} \mathrm{HC} 067047$ versus $1 \times 10^{-7} \mathrm{M}$ oxytocin, ${ }^{\S \S \S} P=0.0005$ for $200 \mathrm{nM} \mathrm{HC} 067047$, and $P=0.0002$ for $1 \mu \mathrm{M} \mathrm{HC} 067047$ versus $1 \times 10^{-6} \mathrm{M}$ oxytocin via two-way ANOVA with $n=4$ to 7. (B) Representative myography tracings for each treatment group at baseline (left) and in response to $1 \times 10^{-6} \mathrm{M}$ oxytocin (right). (C) Myography of uterine muscle strips from pregnant WT mice at D18 was performed while incubating the strips with increasing doses of the TRPV4 activator GSK1016790A in the presence of vehicle (black circles),
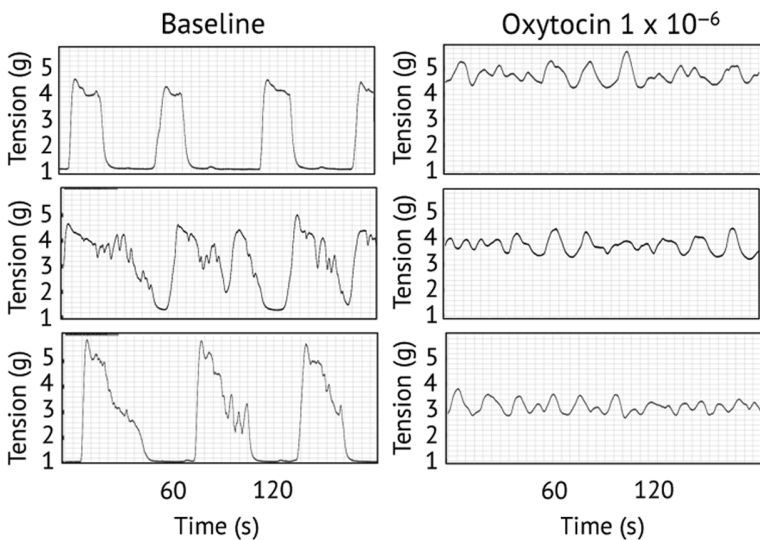

Oxytocin + vehicle

Oxytocin + $\mathrm{HC} 200 \mathrm{nM}$

Oxytocin + $\mathrm{HC} 1 \mu \mathrm{M}$
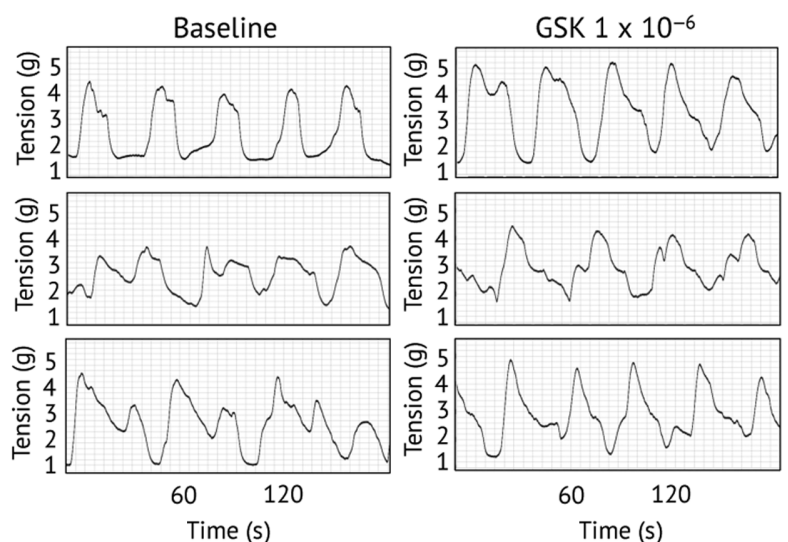

GSK +

vehicle

GSK + HC $200 \mathrm{nM}$

GSK +

$\mathrm{HC} 1 \mu \mathrm{M}$
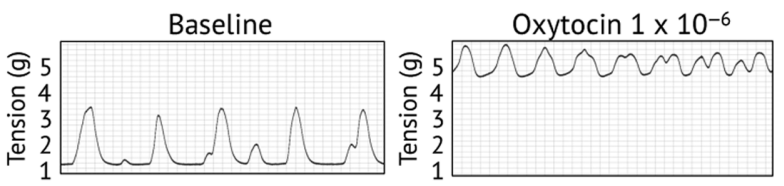

WT
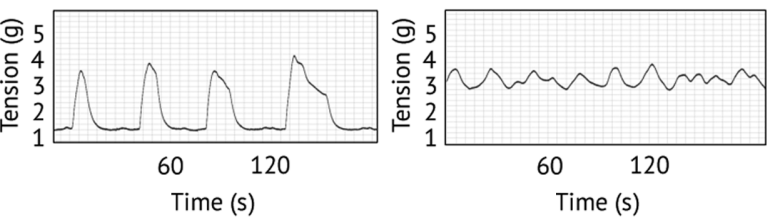

$\operatorname{Trpv4^{-1-}}$
$200 \mathrm{nM} \mathrm{HC} 067047$ (dark gray squares), or $1 \mu \mathrm{M} \mathrm{HC} 067047$ (light gray triangles). ${ }^{* *} P=0.0023$ and ${ }^{* * * *} P<0.0001$ versus $1 \times 10^{-10} \mathrm{M}$ GSK1016790A, ${ }^{\S} P=0.0056$ for $200 \mathrm{nM} \mathrm{HC} 067047$ and $P=0.0076$ for $1 \mu \mathrm{M} \mathrm{HC} 067047$ versus $1 \times 10^{-7} \mathrm{M}$ GSK1016790A, and ${ }^{\S \S \S \S} P<0.0001$ for $200 \mathrm{nM}$ and $1 \mu \mathrm{M} \mathrm{HC} 067047$ versus $1 \times 10^{-6}$ M GSK1016790A via two-way ANOVA with $n=6$ to 8. (D) Representative myography tracings for each treatment group at baseline (left) and in response to $1 \times 10^{-6} \mathrm{M}$ GSK1016790A (right). (E) Myography of uterine muscle strips from pregnant WT mice (black circles) and Trpv4 ${ }^{-1}$ mice (dark gray squares) at D18 was performed while incubating strips with increasing doses of oxytocin. ${ }^{* * * *} P<0.0001$ versus $1 \times 10^{-10} \mathrm{M}$ oxytocin, ${ }^{5} P=0.012$ for Trpv $4^{-1-}$ versus WT at $1 \times 10^{-8} \mathrm{M}$ oxytocin, ${ }^{\S \S \S \S} \mathrm{P}<0.0001$ for Trpv4 ${ }^{/-}$versus WT at $1 \times 10^{-7} \mathrm{M}$ and $1 \times 10^{-6} \mathrm{M}$ oxytocin, and ${ }^{\#}$ versusTrp4 $4^{--}$mice at $1 \times 10^{-10} \mathrm{M}$ oxytocin via two-way ANOVA with $n=4$. (F) Representative myography tracings for each treatment group at baseline (left) and in response to $1 \times 10^{-6} \mathrm{M}$ oxytocin (right). 
A
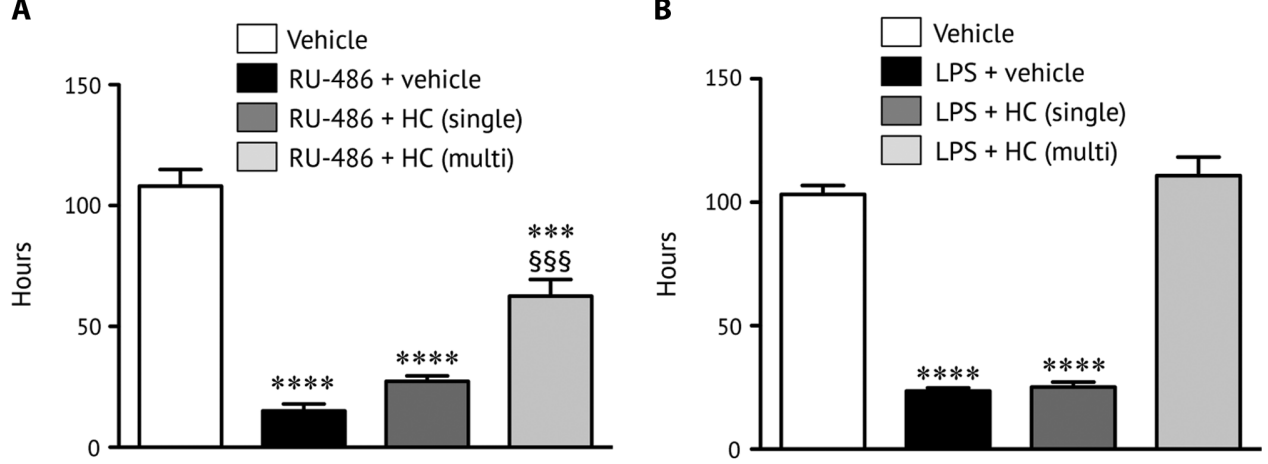

C

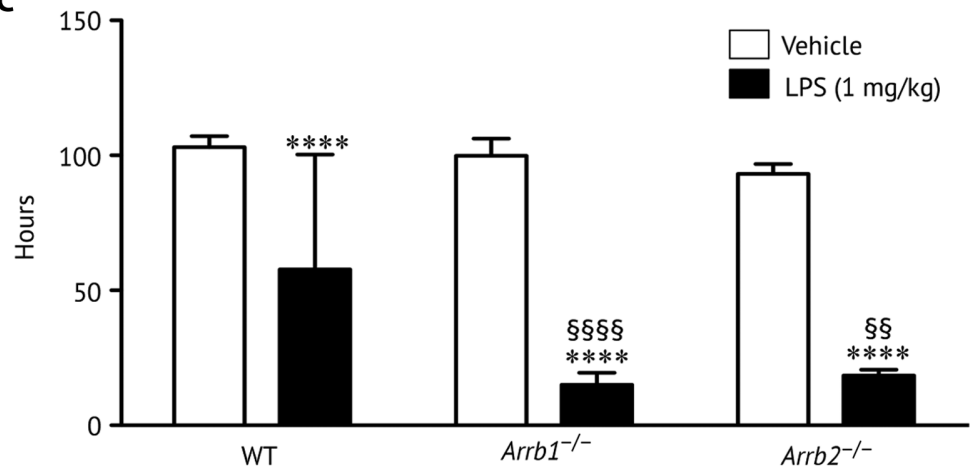

Fig. 6. TRPV4 inhibition protects against preterm labor, whereas loss of $\beta$-arrestin-1 or $\beta$-arrestin-2 increases susceptibility to preterm labor. (A) Pregnant WT mice at D15 were treated with RU-486 $(150 \mu \mathrm{g})$ intraperitoneally, and after 8 hours, groups were treated with vehicle, HC 067047 as a single dose $(20 \mathrm{mg} / \mathrm{kg})$, or multiple doses of HC $067047(10 \mathrm{mg} / \mathrm{kg})$ every 8 hours. The time until delivery of the first pup was recorded. ${ }^{* *} P=$ 0.0002 and ${ }^{* * * *} P<0.0001$ versus vehicle, and ${ }^{\S \S \S} P=0.008$ versus RU-486 + HC 067047 (single) via one-way ANOVA with $n=3$ to 5 per group. (B) Pregnant WT mice at D15 were treated with LPS (3 mg/kg) intraperitoneally, and after 8 hours, groups were treated with vehicle, HC 067047 as a single dose $(20 \mathrm{mg} / \mathrm{kg})$, or multiple doses of HC 067047 $(10 \mathrm{mg} / \mathrm{kg})$ every 8 hours. The time until delivery of the first pup was recorded. ${ }^{* * *} P<0.0001$ versus vehicle via one-way ANOVA with $n=3$ to 6 per group. (C) Pregnant WT, $A r r b 1^{-1-}$, or Arrb2 ${ }^{-1-}$ mice were treated with LPS $(1 \mathrm{mg} / \mathrm{kg})$ intraperitoneally, and the time until delivery of the first pup was recorded. ${ }^{* * *} P<0.0001$ versus vehicle for each genotype, and ${ }^{\S \S} P=0.0018$ and ${ }^{\S \S \S \S} P<0.0001$ versus LPS WT, by two-way ANOVA with $n=4$ per group.

increase in the human uterus during pregnancy. However, difficulties in the procurement of uterine tissue from nonpregnant women of childbearing age resulted in differences in the mean ages of the two study groups, thus limiting the conclusions that might be drawn regarding differential expression of TRPV4 during human pregnancy.

Recent data suggest that TRPV channel activity is modulated, in part, by subcellular trafficking involving dynamic protein-protein interactions. The TRPV4 channel is a specific interacting partner of $\beta$-arrestins (21), a family of proteins that functionally down-regulate $G$ protein (heterotrimeric guanine nucleotide-binding protein) and other transmembrane receptors by inducing conformational changes that prevent receptor coupling or by enhancing receptor internalization via endocytosis $(21,24)$. In vascular SMC, both $\beta$-arrestin- 1 and $\beta$-arrestin- 2 modulate TRPV4 activity and ubiquitination (21) via the binding and recruitment of atrophin 1-interacting protein 4 (AIP4), a member of the HECT homologous to E6-AP C-terminal family of ubiquitin ligases that is the relevant ligase for TRPV4 channel ubiquitination (25). Consequently, the basal activity of TRPV4 might be constrained even in the absence of changes in TRPV4 expression (25).
Consistent with the notion that dynamic protein-protein interactions modulate TRPV channel activity in $\mathrm{mSMC}$, we identified a trend toward decreased $\beta$-arrestin- 1 and $\beta$-arrestin-2 expression as pregnancy moves toward term, although this finding will need to be confirmed in larger data sets. Decreased $\beta$-arrestin- 2 expression can augment the presence of TRPV4 on the cell membrane TRPV4 $(3,21,30)$. Both immunocytochemistry and Western blot analysis of cell membrane fractions demonstrate an increase in TRPV4 expression at the membrane with pregnancy. Our confocal imaging studies were consistent with this construct because TRPV4 expression was more discrete and peripheral in tissue derived from pregnant as opposed to nonpregnant animals. Moreover, results obtained from the PLA confirmed that TRPV4 physically interacts with $\beta$-arrestin-2 in the nonpregnant uterus and that this interaction is diminished during late pregnancy.

Although additional experiments are needed to definitively link the increased membrane localization of TRPV4 in $\mathrm{mSMC}$ with decreases in $\beta$-arrestin expression during pregnancy, data from whole animal studies provide further support for the overall notion, given that $A r r b 1^{-/-}$and $A r r b 2^{-1-}$ null pregnant mice were more sensitive to LPS than wild-type control mice. These data suggest that when $\beta$ arrestin molecules are absent, TRPV channels are either more concentrated on the mSMC membrane at an earlier point in gestation or more abundant overall. Therefore, increased TRPV4 channel expression on the mSMC membrane may underlie the increased sensitivity of the $\beta$ arrestin-null mice to inflammation-induced preterm labor.

Multiple lines of investigation offer support for this construct. Grotegut et al. demonstrated that uterine sensitivity to oxytocin, a molecule that stimulates uterine contractility, is contingent upon $\beta$-arrestins. Specifically, desensitization to oxytocin, which is associated with uterine contractile dysfunction and cesarean section delivery, is mediated by $\beta$-arrestins (31). Moreover, a functional link between TRPV4 and the $\beta$-arrestins has been demonstrated previously (21). These two molecules, together, can finely regulate intracellular $\mathrm{Ca}^{2+}$ signaling and prevent excessive increases in cytosolic calcium $(21,32)$. From an evolutionary perspective, the juxtaposition of these molecules, superimposed on altered levels of expression during pregnancy, may represent a key component in the puzzle of prolonged uterine quiescence during pregnancy punctuated by the high-tone, rhythmic contractions that characterize effective labor.

Data derived from two distinct murine models of preterm labor provided further proof of concept for a functional role for TRPV4 in modulating myometrial contractility. Pregnancy was prolonged by pharmacologic blockade of the TRPV4 channel. In the context 
of inflammation-induced preterm labor, TRPV4 channel antagonism was associated with full-term pregnancy. In addition to modulating intracellular calcium, the TRPV4 channel plays a role in regulating the inflammatory response. Pharmacologic blockade of TRPV4 decreases inflammation in a model of arthritis (33). Activation of TRPV4 in adipocytes promotes an inflammatory phenotype, increasing the expression of numerous cytokines, chemokines, and adhesion molecules (28). In our studies, TRPV4 blockade appeared to prolong pregnancy more effectively in an inflammatory, as compared to endocrine, model, suggesting that TRPV4 might modulate myometrial inflammation; however, definitive evidence is lacking.

Data derived from calcium imaging studies, collagen gel contraction assays, and myography also support a specific role for TRPV4. mSMC calcium transients prompted by TRPV4 channel stimulation were greater and more sustained in cells derived from pregnant, as opposed to nonpregnant, rats. Experiments carried out in collagen gels using a gain- and loss-of-function strategy demonstrated that either oxytocinor inflammation-induced mSMC contraction is contingent upon TRPV4 channel expression. Myography studies further support a central role for the myometrial TRPV4 channel in mediating uterine contractility. In uterine tissue with either deletion or pharmacologic inhibition of the TRPV4 channel, the uterine contractile response to oxytocin was decreased. Conversely, specific pharmacologic activation of TRPV4 augmented myometrial contractility. These data all point to a physiologically relevant role for the TRPV4 channel in uterine quiescence and the uterine contractile response to oxytocin. It is interesting to note that in $A r r b 1^{-1-}$ and $A r r b 2^{-/-}$null mice, the myometrial contractile response to oxytocin is accentuated (31).

Strategies designed to modulate entry of extracellular $\mathrm{Ca}^{2+}$ into $\mathrm{mSMC}$, and thereby contractility, have been less than successful in preventing or halting the progression of preterm labor thus far (34). Our studies address the physiology, molecular expression, and protein trafficking of the mSMC TRPV4 channel during pregnancy and thereby provide insights into the fundamental biology of pregnancy and uterine quiescence and contraction. By demonstrating that modulating TRPV4 channel activity in the context of murine models of preterm labor can prolong pregnancy, our data support the notion that the TRPV4 channel represents a potential therapeutic target to address, in part, preterm labor and delivery, the primary cause of neonatal morbidity and mortality across the world.

\section{MATERIALS AND METHODS}

\section{Study design}

We sought to determine whether the TRPV4 channel modulates uterine contractility. To address this overall objective, we used myometrial tissue and cells from pregnant and nonpregnant rats and mice, human mSMCs, and in vivo studies in two separate mouse models of preterm labor. Myometrial tissue and cells were stimulated with oxytocin, LPS, and pharmacologic activators and antagonists of TRPV4. Myometrial cell cytosolic calcium concentration was measured, and myometrial tone was assessed by myography. For the in vivo studies, experimental animals were randomly assigned to the treatment groups. A single investigator, blinded to the experimental groups, performed the data analysis for the myography studies. Experiments were performed a minimum of three separate times unless otherwise stated in the figure legend.

\section{Rat studies}

We used timed-pregnant Sprague-Dawley rats obtained from Charles River Laboratories. The experimental protocols were approved by the Stanford University animal care and use committee. Rats were housed in a $25^{\circ} \mathrm{C}$ temperature room with alternating 12-hour light and dark cycles. Day 0 of pregnancy was determined by observation of the vaginal plug. Rats generally delivered on the morning of day 22 .

Animals were anesthetized with $2 \%$ isoflurane and euthanized by exsanguination. Subsequently, uterine tissue was procured from nonpregnant and pregnant (days 7, 14, 17, 19, and 21 of gestation), laboring (after the first pup was delivered on day 22), and postpartum ( 3 days after the delivery) rats. The uterus was excised and opened, and the uterine horns were placed in Hanks' balanced salt solution (HBSS) (Gibco). After collection, samples were snap-frozen in liquid nitrogen and stored at $-80^{\circ} \mathrm{C}$ for RNA or protein isolation or used immediately for cell isolation. For each day of gestation, tissues were collected from six different animals and processed for different experimental purposes.

\section{Mouse strains}

Adult C57BL/6 (wild type) (Charles River Laboratories), $\beta$-arrestin-1null $\left(A r r b 1^{-1-}\right), \beta$-arrestin-2-null $\left(A r r b 2^{-/-}\right)$, and TRPV4-null (Trpv4 $\left.4^{--}\right)$ mice female mice were subjected to timed matings, with the morning of vaginal plug detection designated as day 0 of pregnancy. Arrb1 $1^{-1-}$ and $A r r b 2^{-/-}$mice were provided by R. J. Lefkowitz and have been described previously $(35,36)$. $\operatorname{Trp} v 4^{-1-}$ mice were provided by $\mathrm{W}$. Liedtke and have been described previously (37).

\section{Murine preterm labor model}

In separate experiments, pregnant C57BL/6 mice were treated on D15 with either the estrogen antagonist RU-486 (150 $\mu \mathrm{g}$, Roussel Uclaf) or LPS (Escherichia coli 0127:B8, chromatographically pure, Sigma-Aldrich) via the intraperitoneal route. RU-486-treated mice were then treated with either intraperitoneal injections of normal saline $(200 \mu \mathrm{l})$ or one of two treatment (intraperitoneal) regimens with the selective TRPV4 channel antagonist HC 067047 (R\&D Systems). One group received a single dose of HC 067047 (20 mg/kg) and another group received HC 067047 at $10 \mathrm{mg} / \mathrm{kg}$ every 8 hours, beginning 8 hours after RU-486 administration. In the LPS experimental series, timed pregnant mice on D15 were assigned to one of four experimental groups and given intraperitoneal injections of either (i) vehicle (saline, $200 \mu \mathrm{l}$ ), (ii) LPS (3 mg/kg) (Sigma), (iii) LPS + a single dose of HC 067047 (20 mg/kg), or (iv) LPS + multidose HC 067047 (10 mg/kg every 8 hours).

\section{Cell isolation and primary culture of rat mSMCs}

Strips of longitudinal muscle (10 to $20 \mathrm{~mm}$ long) were cut from the serosal surface of the uterine horn, carefully excluding endometrium and circular muscle, and finely chopped into 2- to 3-mm-long pieces in ice-cold HBSS and then incubated with gentle shaking for $40 \mathrm{~min}$ at $37^{\circ} \mathrm{C}$ in $5 \mathrm{ml}$ of HBSS containing $1.5 \mathrm{mM} \mathrm{CaCl}_{2}$, collagenase type IA ( $2 \mathrm{mg} / \mathrm{ml}$ ) (Sigma), trypsin inhibitor ( $2 \mathrm{mg} / \mathrm{ml}$ ) (soybean, type II-S, Sigma), and bovine serum albumin (BSA) $(6 \mathrm{mg} / \mathrm{ml})$ (Sigma). The cell suspension was then triturated 15 to 20 times, filtered through a $40-\mu \mathrm{m}$ sterile filter, and washed twice in minimum essential medium (MEM) (Gibco) containing $10 \%$ fetal calf serum (FCS) by centrifugation $\left(450 \mathrm{~g}, 5 \mathrm{~min}, 20^{\circ} \mathrm{C}\right)$. The cell pellet was suspended in MEM supplemented with $5 \%$ FCS, penicillin $(25 \mathrm{U} / \mathrm{ml})$, and streptomycin $(25 \mathrm{U} / \mathrm{ml})$. For imaging protocols, cell solution $(400 \mu \mathrm{l})$ was placed on glass coverslips and cells were allowed to adhere for about 
1 hour, after which the coverslips were flooded with an additional $1.6 \mathrm{ml}$ of culture medium. For Western blot analysis, myocytes were seeded into $25-\mathrm{cm}^{3}$ culture flasks. Myocytes were incubated at $37^{\circ} \mathrm{C}$ in a humidified atmosphere of $95 \%$ air $/ 5 \% \mathrm{CO}_{2}$ and maintained as a primary culture until confluent (on average, 4 days). The culture medium was changed every 2 to 3 days. To assess the purity of myocyte cultures, we performed immunocytochemistry with $\alpha$-actin (Sigma) and calponin (Abcam) monoclonal antibodies (see details below).

\section{Immunocytochemistry}

After inhalational anesthesia (2\% isoflurane), myometrial SMCs from pregnant and nonpregnant rats were obtained and placed in primary culture. Cells from pregnant rats were obtained at day 21 of gestation and subsequently used for immunolocalization studies and fixed with $4 \%$ paraformaldehyde for $10 \mathrm{~min}$. Rat myometrial SMCs were washed six times with PBS, blocked for 1 hour at room temperature (blocking buffer: $5 \%$ normal goat serum $+4 \%$ BSA in PBS containing $0.1 \%$ Triton $\mathrm{X}-100$ ), and subsequently incubated overnight at $4^{\circ} \mathrm{C}$ with the desired rabbit polyclonal primary antibody. Primary antibody against TRPV4 (Alomone Labs, 1:200) was diluted in blocking buffer. Rat myometrial SMCs were then washed six times with PBS containing $0.1 \%$ Triton $\mathrm{X}-100$, incubated for 1 hour at room temperature in the dark with the mouse Alexa Fluor 488 secondary antibody (Molecular Probes), and washed three more times with PBS. The membrane was stained with CellMask plasma membrane stains from Invitrogen, and the slides were mounted with Vectashield containing DAPI.

\section{Immunofluorescent staining of myometrial tissue}

Uterine tissue was obtained from pregnant and nonpregnant mice, placed in O.C.T., and frozen. Frozen tissue sections were rehydrated and treated for $30 \mathrm{~min}$ with $1 \times \mathrm{PBS} / 0.25 \%$ Triton X-100 solution, and subsequently rinsed in PBS for $5 \mathrm{~min} \times 2$. Tissue sections were then incubated for $40 \mathrm{~min}$ in undiluted Sea Block Blocking Solution (Thermo Scientific), rinsed in PBS, and then incubated in undiluted Fc Receptor Blocker solution (Innovex Biosciences) for $30 \mathrm{~min}$. After being rinsed in PBS, tissue sections were then incubated overnight at $4^{\circ} \mathrm{C}$ with a primary antibody against TRPV4 (1:300, Abcam). Sections were then washed in PBS for $3 \times 10 \mathrm{~min}$ and then incubated with the suitable fluorochrome-labeled secondary antibodies: goat anti-rabbit Alexa Fluor 488 (Invitrogen/Molecular Probes). Chromatin was counterstained with Hoechst reagent $(10 \mathrm{mg} / \mathrm{ml})$ (Sigma-Aldrich) diluted in $\mathrm{H}_{2} \mathrm{O}(1: 10,000)$. Specimens were examined by confocal microscopy with an Olympus FV-1000 laser scanning confocal microscope $(\mathrm{HeNe} / \mathrm{Ar}) \times 60$ water immersion objective, and images were processed with the FluoView software (Olympus). Selected frames are representative images.

\section{Quantitative real-time PCR}

Quantitative real-time PCR (RT-PCR) was performed to determine Trpv4 gene expression at different time points during gestation in the rat uterus. Total RNA was extracted from the frozen tissues and from the frozen pellet of rat SMC using TRIzol (Invitrogen) according to the manufacturer's instructions. RNA samples were column-purified using RNeasy Mini Kit (Qiagen). After quantification, $2 \mu \mathrm{g}$ of total RNA was used to synthesize single-stranded complementary DNA (cDNA) using $200 \mathrm{IU}$ of SuperScript III reverse transcriptase (Invitrogen). Then, cDNA was subjected to RT-PCR using validated primer and probe sets for TRPV4, which were obtained from Applied Biosystems, and $18 S$ ribosomal RNA from IDT. Quantitative PCR was performed in the presence of either
FAM (for TRPV4) or SYBR Green (for 18S) (Applied Biosystems), and amplicon yield was monitored during cycling in an ABI PRISM 7000 Sequence Detection System (Applied Biosystems Ltd.). A comparative $C_{\mathrm{t}}$ method ( $\Delta \Delta C_{\mathrm{t}}$ method) was applied to the raw $C_{\mathrm{t}}$ values to evaluate relative gene expression. The expression of each TRPV gene on a specific gestational day calculated in reference to the individual calibration curves was normalized to the amount of ribosomal $18 S$ mRNA.

\section{Protein isolation from rat myometrial tissue and smooth muscle cells}

Confluent primary cultured rat mSMCs were washed with PBS. Cells were detached from culture flasks by scraping in ice-cold PBS and centrifuged at $4000 \mathrm{~g}$ for $5 \mathrm{~min}$ at $4^{\circ} \mathrm{C}$, and the pellets were snap-frozen in liquid nitrogen and stored at $-80^{\circ} \mathrm{C}$ until required. Myometrial tissue was crushed in liquid nitrogen using a mortar and pestle, then homogenized in $500 \mu \mathrm{l}$ of lysis buffer [50 mM tris- $\mathrm{HCl}, 150 \mathrm{mM}$ $\mathrm{NaCl}, 1 \%$ deoxycholic acid, $0.1 \%$ SDS, $0.5 \%$ NP-40, Complete protease inhibitor cocktail (Roche), $1 \mathrm{mM}$ phenylmethylsulfonyl fluoride], and centrifuged at $3000 \mathrm{~g}$ for $10 \mathrm{~min}$ at $4^{\circ} \mathrm{C}$. The supernatant was collected, and protein concentrations were determined using the BCA protein assay kit (Thermo Scientific).

\section{Western blotting}

Myometrial protein $(30 \mu \mathrm{g})$ was denatured at $70^{\circ} \mathrm{C}$ for $10 \mathrm{~min}$ in $4 \times \mathrm{LDS}$ sample buffer (Invitrogen), size-separated using Novex 4-12\% Bis-Tris Mini Gels (Invitrogen), and then transferred to polyvinylidene difluoride membrane (Immobilon, Millipore). After transfer, membranes were incubated for 1 hour at room temperature in blocking buffer (PBS-T: $0.1 \%$ Tween 20, Sigma, 5\% nonfat dry milk) and subsequently incubated overnight at $4^{\circ} \mathrm{C}$ with the desired rabbit polyclonal primary antibody. Primary antibodies used were TRPV4 (Alomone Labs, 1:200), ARRB1 (BD Transduction Lab, \#610550), and ARRB2 (Abcam, ab31294), which were diluted in blocking buffer. For negative controls, membranes were incubated with primary antibodies that were preabsorbed (1 hour, room temperature) with the respective peptides, as recommended by the supplier. After incubation with the primary antibody or negative control, membranes were washed in PBS-T $(3 \times 15 \mathrm{~min})$ and then incubated for 1 hour at room temperature with horseradish peroxidase-conjugated donkey anti-rabbit secondary antibody diluted 1:5000 in blocking buffer. Thereafter, membranes were washed in PBS-T $(3 \times 15 \mathrm{~min})$, and protein bands were visualized with enhanced chemiluminescence (Pierce).

\section{Fluorescent in situ PLA (PLA-Duolink)}

To determine whether TRPV4 and ARRB2 physically interact, we used a PLA. PLA, an antibody-based technique, is capable of visualizing protein-protein interactions (38) and has the advantage of providing an "in situ" snapshot of the proteins of interest. A PLA signal is generated when the distance between the two secondary antibodies is less than $16 \mathrm{~nm}$ (39). Frozen uterus muscle strips were sliced $(3 \mu \mathrm{m})$ and placed on a glass coverslip $(25 \mathrm{~mm} \times 75 \mathrm{~mm} \times 1 \mathrm{~mm})$. PLA assay was performed using Duolink In Situ kit (Olink Bioscience) according to the manufacturer's instructions. In brief, tissues were blocked and incubated with the appropriate primary antibodies (TRPV4, 1:300; ARRB2, 1:100; Abcam) diluted in antibody diluent overnight at $4^{\circ} \mathrm{C}$ in a moist chamber. Proximity ligation was then conducted in situ. We used the Duolink II PLA Probe Anti-Rabbit PLUS, Duolink II PLA Probe Anti-Goat MINUS, and Duolink II Detection Reagents 563 to 
visualize interactions. After serial washes in buffer A (0.01 M tris, $0.15 \mathrm{M} \mathrm{NaCl}$, and $0.05 \%$ Tween 20$)$ and buffer B (0.2 M tris and $0.1 \mathrm{M} \mathrm{NaCl}$ ) for $1 \mathrm{~min}$, the slides were air-dried and mounted with the Duolink Mounting Medium, and images of five random fields were captured for each tissue.

\section{Human uterine SMC contraction assay}

Collagen gel contraction assays were performed as previously described (40) with modification. Collagen $(150 \mu \mathrm{l})$ was aliquoted per well of a 48-well plate. After 1 hour of polymerization, 40,000 human uterine SMCs, transfected with either nontargeted control (NTC) siRNA or TRPV siRNA for 48 hours, were added to each well in $300 \mu \mathrm{l}$ of SmBM smooth muscle basic medium (Lonza). Collagen gels were exposed to either PBS (controls), LPS (100 ng/ml), or oxytocin (100 nM). After incubating for 1 hour at $37^{\circ} \mathrm{C}$ and $5 \% \mathrm{CO}_{2}$, the sides of the collagen gels were detached from the wells with sterile $200-\mu$ l pipette tips. After 18 hours, cells in collagen-coated wells were fixed with $4 \%$ paraformaldehyde solution for $30 \mathrm{~min}$, then rinsed, and stored in PBS. Experiments were done multiple times $(n=4)$, with triplicates for each condition. Area of each gel was measured using the AmScope software. In brief, the cross-sectional diameter of each gel was measured (two diameter measurements per gel sample). The following formula was used to determine the area of a circle: $(\pi)(r)^{2}$, where $r$ is the radius. Mean surface area was determined using two distinct diameter measurements. The areas were then expressed as a percentage relative to the area of no cell control (set at 100\%) $(P<0.001)$.

\section{Myography of mouse uterine strips}

Timed-pregnant wild-type C57/B6 and $\operatorname{Tr} v v 4^{-1-}$ mice were anesthetized with isoflurane and euthanized before making a vertical midline abdominal incision and removing each of the two uterine horns. Uterine horns were subsequently cut into $3-\mathrm{mm} \times 7$-mm segments and placed in a modified Krebs buffer $\left(118 \mathrm{mM} \mathrm{NaCl}, 4.8 \mathrm{M} \mathrm{KCl}, 1.2 \mathrm{mM} \mathrm{MgSO}_{4}\right.$, $1.2 \mathrm{mM} \mathrm{KH}_{2} \mathrm{PO}_{4}, 2.5 \mathrm{mM} \mathrm{CaCl}_{2}, 25 \mathrm{mM} \mathrm{NaHCO}_{3}$, and $11 \mathrm{mM}$ glucose, $\mathrm{pH}$ 7.4). Muscle segments were vertically suspended on custom-made stainless steel hooks inside an organ bath filled with modified Krebs buffer, maintained at $37^{\circ} \mathrm{C}$, and aerated with gas containing $95 \% \mathrm{O}_{2}$ and $5 \% \mathrm{CO}_{2}$. The strips were allowed to equilibrate at $1.5 \mathrm{~g}$ of tension for $60 \mathrm{~min}$. All uterine strips demonstrated a spontaneous contraction pattern. For the oxytocin dose-response experiments, the strips were then stimulated with oxytocin at concentrations ranging from 1 to $1000 \mathrm{nM}$, and the pattern of contraction in response to each dose was recorded for $9 \mathrm{~min}$. The muscle strips were washed with Krebs solution twice and allowed to equilibrate for $3 \mathrm{~min}$ before the next stimulation. In separate experiments, strips were treated with the HC 067047 compound at one of two doses before assessing the dose response to oxytocin. Strips were also treated with the TRPV4 channel agonist GSK1016790A at concentrations ranging between 1 and $1000 \mathrm{nM}$ in the presence and absence of the HC 067047 compound. In a separate series of experiments, muscle strips from TRPV4-null mice were treated with increasing doses of oxytocin. Contraction tracings were recorded using PowerLab and LabChart (ADInstruments). The area under the curve was calculated for the final 3 min of each 9-min contraction tracing using GraphPad Prism (GraphPad Prism for Macintosh version 5.0; GraphPad Software). The area under the curve for each response was then normalized to the area under the curve for the spontaneous contraction pattern over the 5-min period that immediately preceded the challenge.

\section{Statistical analysis}

Results are expressed as means \pm SEM. Statistical significance was assessed with Student's $t$ test (for normally distributed samples), Mann-Whitney $U$ test (for samples that were not normally distributed), and one- or twoway ANOVA where appropriate. A $P$ value of $<0.05$ was taken as the threshold for statistical significance. All experiments were repeated a minimum of three times unless stated otherwise.

\section{SUPPLEMENTARY MATERIALS}

www.sciencetranslationalmedicine.org/cgi/content/full/7/319/319ra204/DC1

Fig. S1. TRPV4 expression is increased in pregnant human uterine tissue.

\section{REFERENCES AND NOTES}

1. D. J. Lyell, K. Pullen, L. Campbell, S. Ching, M. L. Druzin, U. Chitkara, D. Burrs, A. B. Caughey, Y. Y. El-Sayed, Magnesium sulfate compared with nifedipine for acute tocolysis of preterm labor: A randomized controlled trial. Obstet. Gynecol. 110, 61-67 (2007).

2. D. J. Lyell, K. M. Pullen, J. Mannan, U. Chitkara, M. L. Druzin, A. B. Caughey, Y. Y. El-Sayed, Maintenance nifedipine tocolysis compared with placebo: A randomized controlled trial. Obstet. Gynecol. 112, 1221-1226 (2008).

3. H. Wei, S. Ahn, S. K. Shenoy, S. S. Karnik, L. Hunyady, L. M. Luttrell, R. J. Lefkowitz, Independent $\beta$-arrestin 2 and $\mathrm{G}$ protein-mediated pathways for angiotensin II activation of extracellular signal-regulated kinases 1 and 2. Proc. Natl. Acad. Sci. U.S.A. 100, 10782-10787 (2003).

4. R. Smith, Parturition. N. Engl. J. Med. 356, 271-283 (2007).

5. J. R. G. Challis, S. G. Matthews, W. Gibb, S. J. Lye, Endocrine and paracrine regulation of birth at term and preterm. Endocr. Rev. 21, 514-550 (2000).

6. R. M. Tribe, P. Moriarty, L. Poston, Calcium homeostatic pathways change with gestation in human myometrium. Biol. Reprod. 63, 748-755 (2000).

7. S. Wray, A. Shmygol, Role of the calcium store in uterine contractility. Semin. Cell Dev. Biol. 18, 315-320 (2007).

8. D. L. Lefebvre, A. Giaid, H. Bennett, R. Larivière, H. H. Zingg, Oxytocin gene expression in rat uterus. Science 256, 1553-1555 (1992).

9. B. M. Sanborn, lon channels and the control of myometrial electrical activity. Semin. Perinatol. 19, 31-40 (1995).

10. C. Roos, M. E. A. Spaanderman, E. Schuit, K. W. M. Bloemenkamp, A. C. Bolte, J. Cornette, J. J. J. Duvekot, J. van Eyck, M. T. M. Franssen, C. J. de Groot, J. H. Kok, A. Kwee, A. Merién, B. Nij Bijvank, B. C. Opmeer, M. A. Oudijk, M. G. van Pampus, D. N. M. Papatsonis, M. M. Porath, H. C. J. Scheepers, S. A. Scherjon, K. M. Sollie, S. M. C. Vijgen, C. Willekes, B. W. J. Mol, J. A. M. van der Post, F. K. Lotgering; APOSTEL-II Study Group, Effect of maintenance tocolysis with nifedipine in threatened preterm labor on perinatal outcomes: A randomized controlled trial. JAMA 309, 41-47 (2013).

11. S. Earley, T. J. Heppner, M. T. Nelson, J. E. Brayden, TRPV4 forms a novel $\mathrm{Ca}^{2+}$ signaling complex with ryanodine receptors and BK $\mathrm{Ca}_{\text {a }}$ channels. Circ. Res. 97, 1270-1279 (2005).

12. C. Montell, L. Birnbaumer, V. Flockerzi, The TRP channels, a remarkably functional family. Cell 108, 595-598 (2002).

13. R. Strotmann, C. Harteneck, K. Nunnenmacher, G. Schultz, T. D. Plant, OTRPC4, a nonselective cation channel that confers sensitivity to extracellular osmolarity. Nat. Cell Biol. 2, 695-702 (2000).

14. H. Watanabe, J. Vriens, S. H. Suh, C. D. Benham, G. Droogmans, B. Nilius, Heat-evoked activation of TRPV4 channels in a HEK293 cell expression system and in native mouse aorta endothelial cells. J. Biol. Chem. 277, 47044-47051 (2002).

15. L. Wu, X. Gao, R. C. Brown, S. Heller, R. G. O'Neil, Dual role of the TRPV4 channel as a sensor of flow and osmolality in renal epithelial cells. Am. J. Physiol. Renal Physiol. 293, F1699-F1713 (2007).

16. V. Singh, M. Ram, K. Kandasamy, R. Thangamalai, S. Choudhary, J. R. Dash, D. Kumar, S. Parida, T. U. Singh, S. K. Mishra, Molecular and functional characterization of TRPV4 channels in pregnant and nonpregnant mouse uterus. Life Sci. 122, 51-58 (2015).

17. D. Becker, C. Blase, J. Bereiter-Hahn, M. Jendrach, TRPV4 exhibits a functional role in cellvolume regulation. J. Cell Sci. 118, 2435-2440 (2005).

18. V. Benfenati, M. Caprini, M. Dovizio, M. N. Mylonakou, S. Ferroni, O. P. Ottersen, M. Amiry-Moghaddam, An aquaporin-4/transient receptor potential vanilloid 4 (AQP4/TRPV4) complex is essential for cell-volume control in astrocytes. Proc. Natl. Acad. Sci. U.S.A. 108, 2563-2568 (2011).

19. C. D. Benham, M. J. Gunthorpe, J. B. Davis, TRPV channels as temperature sensors. Cell Calcium 33, 479-487 (2003).

20. Y. Fu, A. Subramanya, D. Rozansky, D. M. Cohen, WNK kinases influence TRPV4 channel function and localization. Am. J. Physiol. Renal Physiol. 290, F1305-F1314 (2006). 
21. A. K. Shukla, J. Kim, S. Ahn, K. Xiao, S. K. Shenoy, W. Liedtke, R. J. Lefkowitz, Arresting a transient receptor potential (TRP) channel: $\beta$-Arrestin 1 mediates ubiquitination and functional down-regulation of TRPV4. J. Biol. Chem. 285, 30115-30125 (2010).

22. T. A. Rose-Hellekant, B. D. Bavister, Precocious oocyte maturation is induced by an inhibitor of cAMP-dependent protein kinase in the intact golden hamster. Mol. Reprod. Dev. 44, 250-255 (1996).

23. A. R. S. Santos, J. B. Calixto, Ruthenium red and capsazepine antinociceptive effect in formalin and capsaicin models of pain in mice. Neurosci. Lett. 235, 73-76 (1997).

24. J. A. Pitcher, N. J. Freedman, R. J. Lefkowitz, G protein-coupled receptor kinases. Annu. Rev. Biochem. 67, 653-692 (1998).

25. T. Wegierski, K. Hill, M. Schaefer, G. Walz, The HECT ubiquitin ligase AIP4 regulates the cell surface expression of select TRP channels. EMBO J. 25, 5659-5669 (2006).

26. C. Kelley, P. D'Amore, H. B. Hechtman, D. Shepro, Microvascular pericyte contractility in vitro: Comparison with other cells of the vascular wall. J. Cell Biol. 104, 483-490 (1987).

27. W. Everaerts, X. Zhen, D. Ghosh, J. Vriens, T. Gevaert, J. P. Gilbert, N. J. Hayward, C. R. McNamara, F. Xue, M. M. Moran, T. Strassmaier, E. Uykal, G. Owsianik, R. Vennekens, D. De Ridder, B. Nilius, C. M. Fanger, T. Voets, Inhibition of the cation channel TRPV4 improves bladder function in mice and rats with cyclophosphamide-induced cystitis. Proc. Natl. Acad. Sci. U.S.A. 107, 19084-19089 (2010).

28. L. Ye, S. Kleiner, J. Wu, R. Sah, R. K. Gupta, A. S. Banks, P. Cohen, M. J. Khandekar, P. Bostrom, R. J. Mepani, D. Laznik, T. M. Kamenecka, X. Song, W. Liedtke, V. K. Mootha, P. Puigserver, P. R. Griffin, D. E. Clapham, B. M. Spiegelman, TRPV4 is a regulator of adipose oxidative metabolism, inflammation, and energy homeostasis. Cell 151, 96-110 (2012).

29. M. Cella, M. G. Farina, A. P. Dominguez Rubio, G. Di Girolamo, M. L. Ribeiro, A. M. Franchi, Dual effect of nitric oxide on uterine prostaglandin synthesis in a murine model of preterm labour. Br. J. Pharmacol. 161, 844-855 (2010).

30. K. Xiao, D. B. McClatchy, A. K. Shukla, Y. Zhao, M. Chen, S. K. Shenoy, J. R. Yates III, R. J. Lefkowitz, Functional specialization of $\beta$-arrestin interactions revealed by proteomic analysis. Proc. Natl. Acad. Sci. U.S.A. 104, 12011-12016 (2007).

31. C. A. Grotegut, L. Feng, L. Mao, R. P. Heine, A. P. Murtha, H. A. Rockman, $\beta$-Arrestin mediates oxytocin receptor signaling, which regulates uterine contractility and cellular migration. Am. J. Physiol. Endocrinol. Metab. 300, E468-E477 (2011).

32. A. Saxena, M. Bachelor, Y. H. Park, F. R. Carreno, T. P. Nedungadi, J. T. Cunningham, Angiotensin II induces membrane trafficking of natively expressed transient receptor potential vanilloid type 4 channels in hypothalamic 4B cells. Am. J. Physiol. Regul. Integr. Comp. Physiol. 307, R945-R955 (2014).

33. A. Denadai-Souza, L. Martin, M. A. Vieira de Paula, M. C. W. de Avellar, M. N. Muscará, N. Vergnolle, N. Cenac, Role of transient receptor potential vanilloid 4 in rat joint inflammation. Arthritis Rheum. 64, 1848-1858 (2012).

34. L. J. Muglia, M. Katz, The enigma of spontaneous preterm birth. N. Engl. J. Med. 362, 529-535 (2010).
35. L. M. Bohn, R. J. Lefkowitz, R. R. Gainetdinov, K. Peppel, M. G. Caron, F.-T. Lin, Enhanced morphine analgesia in mice lacking $\beta$-arrestin 2. Science 286, 2495-2498 (1999).

36. D. A. Conner, M. A. Mathier, R. M. Mortensen, M. Christe, S. F. Vatner, C. E. Seidman, J. G. Seidman $\beta$-Arrestin1 knockout mice appear normal but demonstrate altered cardiac responses to $\beta$-adrenergic stimulation. Circ. Res. 81, 1021-1026 (1997)

37. W. Liedtke, J. M. Friedman, Abnormal osmotic regulation in trpv $4^{-/-}$mice. Proc. Natl. Acad. Sci. U.S.A. 100, 13698-13703 (2003)

38. O. Söderberg, K.-J. Leuchowius, M. Gullberg, M. Jarvius, I. Weibrecht, L.-G. Larsson, U. Landegren, Characterizing proteins and their interactions in cells and tissues using the in situ proximity ligation assay. Methods 45, 227-232 (2008).

39. P. Trifilieff, M.-L. Rives, E. Urizar, R. A. Piskorowski, H. D. Vishwasrao, J. Castrillon, C. Schmauss, M. Slättman, M. Gullberg, J. A. Javitch, Detection of antigen interactions ex vivo by proximity ligation assay: Endogenous dopamine D2-adenosine A2A receptor complexes in the striatum. Biotechniques 51, 111-118 (2011).

40. T. Kita, Y. Hata, R. Arita, S. Kawahara, M. Miura, S. Nakao, Y. Mochizuki, H. Enaida, Y. Goto, H. Shimokawa, A. Hafezi-Moghadam, T. Ishibashi, Role of TGF- $\beta$ in proliferative vitreoretinal diseases and ROCK as a therapeutic target. Proc. Natl. Acad. Sci. U.S.A. 105, 17504-17509 (2008).

Acknowledgments: We thank R. J. Lefkowitz and W. Liedtke for sharing the Arrb1 ${ }^{-1-}$ and Arrb2 $2^{-1-}$ mice and the $\operatorname{Trpv}^{-/-}$mice, respectively. Funding: The work has been supported by the Burroughs Welcome Fund, the Preterm Birth Initiative, the March of Dimes Prematurity Research Center at Stanford, and the Stanford Child Health Research Institute Tashia and John Morgridge Faculty Scholar Award. Further support for this work derived from the NIH [HL060784 (D.N.C.), HL0706280 (D.N.C.), and HL122918 (C.M.A.)]. Author contributions: L.Y., M.B., and C.I.H. designed and performed experiments, analyzed the data, and wrote the manuscript. X.H. and L.S. performed experiments and analyzed components of the data. D.L. provided the biopsy specimens and managed the protocols for the clinical component of the trial. C.M.A. and D.N.C. contributed equally to the experimental design, study supervision, data analysis, and editing and revising of the manuscript. Competing interests: The authors declare that they have no competing interests.

Submitted 16 July 2015

Accepted 10 November 2015

Published 23 December 2015

10.1126/scitranslmed.aad0376

Citation: L. Ying, M. Becard, D. Lyell, X. Han, L. Shortliffe, C. I. Husted, C. M. Alvira, D. N. Cornfield, The transient receptor potential vanilloid 4 channel modulates uterine tone during pregnancy. Sci. Transl. Med. 7, 319ra204 (2015). 


\section{Science Translational Medicine}

\section{The transient receptor potential vanilloid 4 channel modulates uterine tone during pregnancy}

Lihua Ying, Margaux Becard, Deirdre Lyell, Xiaoyuan Han, Linda Shortliffe, Cristiana losef Husted, Cristina M. Alvira and David N. Cornfield

Sci Transl Med 7, 319ra204319ra204.

DOI: 10.1126/scitransImed.aad0376

\section{TRPing up preterm labor}

The biology of preterm labor, the leading cause of perinatal complications and deaths worldwide, is not yet well understood, and there is no effective treatment. Ying et al. have now uncovered the role of a calcium channel called TRPV4 (transient receptor potential vanilloid 4) in uterine contractility. The amount of TRPV4 gradually increases throughout gestation, explaining its ability to facilitate uterine contractions at term despite maintaining uterine quiescence earlier in pregnancy. The authors also demonstrated that blocking TRPV4 successfully prolonged pregnancy in two mouse models of preterm labor, suggesting that it may be a viable target for interventions to treat preterm labor in human patients.

ARTICLE TOOLS

SUPPLEMENTARY MATERIALS http://stm.sciencemag.org/content/7/319/319ra204

http://stm.sciencemag.org/content/suppl/2015/12/22/7.319.319ra204.DC1
RELATED

CONTENT

REFERENCES

PERMISSIONS

\begin{abstract}
http://stm.sciencemag.org/content/scitransmed/7/319/319fs51.full http://stm.sciencemag.org/content/scitransmed/7/290/290ra88.full http://stm.sciencemag.org/content/scitransmed/6/263/263ed21.full http://stm.sciencemag.org/content/scitransmed/6/262/262sr5.full http://stm.sciencemag.org/content/scitransmed/6/245/245ra92.full http://stke.sciencemag.org/content/sigtrans/8/400/fs 19. full http://stm.sciencemag.org/content/scitransmed/8/350/350ra102.full http://stm.sciencemag.org/content/scitransmed/8/364/364ra154.full http://stke.sciencemag.org/content/sigtrans/8/391/ra85.full http://stke.sciencemag.org/content/sigtrans/8/391/pc21.full http://science.sciencemag.org/content/sci/357/6352/707.full http://stke.sciencemag.org/content/sigtrans/10/500/eaal4055.full http://stm.sciencemag.org/content/scitransmed/13/576/eabc6245.full http://stm.sciencemag.org/content/scitransmed/13/592/eabd9898.full
\end{abstract}

This article cites 40 articles, 15 of which you can access for free http://stm.sciencemag.org/content/7/319/319ra204\#BIBL

http://www.sciencemag.org/help/reprints-and-permissions

Use of this article is subject to the Terms of Service

Science Translational Medicine (ISSN 1946-6242) is published by the American Association for the Advancement of Science, 1200 New York Avenue NW, Washington, DC 20005. The title Science Translational Medicine is a registered trademark of AAAS.

Copyright $@ 2015$, American Association for the Advancement of Science 